\title{
Computational and Experimental Investigation of using an Extractor in a Vertical Gravitational Flash Tank Separator
}

\author{
R. A. Mahmood", D. Buttsworth and R. Malpress \\ School of Mechanical and Electrical Engineering, University of Southern Queensland \\ 487-535 West Street, Toowoomba Qld 4350, Australia \\ *Email: raidalnuaimi@yahoo.com
}

\begin{abstract}
A vertical gravitational flash tank separator can be used to increase the performance of a refrigeration cycle. Using the vertical gravitational flash tank separator improves the effective area and enhances the heat transfer coefficient inside the evaporator. However, the vertical gravitational flash tank separator still needs further investigation to improve its performance. This paper provides an investigation study to demonstrate the improvement of separation efficiency using an extractor inside the vertical gravitational flash tank separator. Computational Fluid Dynamic (CFD) was used to assess the optimum configuration and dimension of the extractor. A series of experiments were performed to test and confirm the proposed CFD configuration of the extractor design. The results revealed that the extractor had increased the separation efficiency by $2 \%$. The CFD simulations gave a good agreement with the experiments; however, all the simulations underestimated the liquid separation efficiency by approximately 0.02 over the range of conditions tested.
\end{abstract}

Keywords: Vertical flash tank; CFD, liquid separator; two-phase flow; liquid separation enhancements.

\section{NOMENCLATURE}

A

CFD

$\mathrm{D}$

G

$\mathrm{h}$

$\mathrm{h}_{\mathrm{g}}$

$\mathrm{h}_{\mathrm{f}}$

$\mathrm{h}_{\mathrm{fg}}$

LVF

$\mathrm{m}_{\mathrm{L} \text {, outlet }}$

$\mathrm{m}_{\mathrm{L}, \text { inlet }}$

$\mathrm{m}_{\mathrm{t}}$

$\mathrm{m}_{\mathrm{g}}$

$\mathrm{m}_{\mathrm{i}}$

$\mathrm{p}$

$\mathrm{u}_{1}$ total cross-section area $\left(\mathrm{m}^{2}\right)$

computational fluid dynamic

tube diameter $(\mathrm{mm})$

total mass flux $\left(\mathrm{kg} / \mathrm{m}^{2} . \mathrm{s}\right)$

specific enthalpy of vapour (J/kg.K)

saturated enthalpy of vapour (J/kg.K)

saturated enthalpy of liquid (J/kg.K)

difference between the specific enthalpy of the saturated vapour and saturated liquid (J/kg.K)

liquid volume fraction

liquid mass flow rate at the liquid outlet of separator $(\mathrm{kg} / \mathrm{s})$

liquid mass flow rate at the inlet of separator $(\mathrm{kg} / \mathrm{s})$

total mass flow rate at the inlet of separator $(\mathrm{kg} / \mathrm{s})$

vapour mass flow rate $(\mathrm{kg} / \mathrm{s})$

liquid mass flow rate $(\mathrm{kg} / \mathrm{s})$

pressure $(\mathrm{kPa})$

local liquid velocity $(\mathrm{m} / \mathrm{s})$ 


$\begin{array}{ll}\mathrm{u}_{\mathrm{g}} & \text { local vapour velocity }(\mathrm{m} / \mathrm{s}) \\ \mathrm{T} & \text { temperature }\left({ }^{\circ} \mathrm{C}\right) \\ \text { VFT-V5 } & \text { based configuration of vertical flash tank separator } \\ \text { VFT-V5-EXR } & \begin{array}{l}\text { proposed configuration of vertical flash tank separator } \\ \text { vapour quality }\end{array} \\ \mathrm{x} & \\ \text { Greek letters } & \text { phase volume fraction. } \\ \alpha & \text { homogeneous void fraction } \\ \alpha_{\mathrm{hg}} & \text { vapour density }\left(\mathrm{kg} / \mathrm{m}^{3}\right) \\ \rho_{\mathrm{g}} & \text { liquid density }\left(\mathrm{kg} / \mathrm{m}^{3}\right) \\ \rho_{1} & \end{array}$

\section{INTRODUCTION}

Air-conditioning, refrigeration and heat pump systems are used widely in domestic and commercial sectors, and these systems use similar components [1]. Many studies have been conducted to enhance the main components of mechanical refrigeration systems such as compressors, fans and heat exchangers, and other work investigates cycle performance and attempts to reduce energy consumption. The vapour injection technique using a vertical gravitational flash tank is an effective way to improve the system's coefficient of performance (COP). In refrigeration systems which use a vapour injection technique, the vertical gravitational flash tank separator feeds the evaporator with the separated liquid, and the vapour is injected into the compressor [2]. In mechanical vapour injection systems, the addition of a flash tank separator can play a crucial role in enhancing the cooling capacity and system performance [3]. This modification reduces the high fraction of vapour (flash gas) at the inlet of the evaporator which is advantageous because (1) the vapour's heat transfer coefficient is lower than the liquid phase; and (2) an increased pressure drop is also experienced with the high void fraction which exists with the presence of vapour [4]. Therefore, when the performance of the vertical gravitational flash tank separator is improved, the performance of the overall system will be improved.

There are many ways to improve the performance of a separator, including the introduction of inlet devices, wire meshes and mist extractors [5]. Inlet devices reduce the momentum of the inlet stream and enhance the flow distribution of the gas and liquid phases inside the separator. The inlet device can be a diverter plate, half-pipe or vane [5]. A wire mesh and mist extractor can effectively be used to separate the liquid drops that move with the gas through the gas outlet as it is not economical to separate these drops by gravity alone by making the separator larger [6].

Some studies reported configurations that can be used to improve the separation performance, for example, inlet devices provide other configurations that can be used to improve the separation performance, and generating momentum force inside the separator to produce a swirling flow can also improve the performance of the vertical separator [7]. Increasing the angle of inclination of the inlet pipe of the vertical flash tank separator is another technique to increase the liquid separation efficiency of the vertical flash tank separator. It also reduces the liquid's impingement on the wall of the separator [3]. The literature also revealed that the two-phase flow pattern at the inlet to the vertical flash tank separator has a significant effect on the separation efficiency. For example, the liquid separation efficiency becomes higher than $45 \%$ when the flow pattern at the inlet is annular, while the liquid separation efficiency becomes higher than $80 \%$ for slug flow at 
low liquid superficial velocity, but the liquid separation efficiency becomes essentially $100 \%$ for stratified flow [8]. Refrigerant R134A has been used widely to investigate the separation efficiency in a vertical separator by several researchers including Hanfei and Hrnjak [3] and Zheng, Zhao [9], while others, notably Wang [7] and Grodal and Realff [10] used different configurations of the vertical separator. Critical droplet size technique can also be considered as a way to assess the separation efficiency, which is based on the terminal velocity. To obtain an efficient separation efficiency, the vapour velocity for a vertical separator should be $75 \%$ to $90 \%$ of the terminal velocity and the appropriate value depends on the working fluid properties and droplet size [11].

Computational Fluid Dynamic (CFD) has been used to design and assess different applications of the two-phase flow. For example, Xiong, Lu [12] used CFD simulation to investigate the two-phase flow inside a swirl-vane separator and to analyse the separation performance. A mixture of air and water was used as the working fluid. The results revealed that the separation efficiency of the swirl-vane separator depends on the flow pattern and the water velocity, while the pressure drop is mainly affected by the air flow rate and water droplet diameter. The CFD simulation results agreed with the experimental results, but the difference between the CFD simulation and experimental results was not quantified. The CFD simulations provide insight into the two-phase behaviour and features that cannot be analysed from any empirical approach [13]. Another advantage of CFD is that it can also be used as one of the design tools to obtain the optimum geometry and dimension [14].

The existing studies demonstrated that there is a further need to establish fundamental design options for optimising the vertical gravitational flash tank separator and its configurations that can be used to improve the separation performance. This paper provides CFD simulations and experimental investigations to improve the separation performance of the vertical gravitational flash tank separator using an extractor as an enhancer inside the separator. This work also provides experimental results that contribute additional knowledge for the design of the vertical gravitational flash tank separator using the experimental operating conditions in the CFD simulations as a design tool when the water is used as the working fluid.

\section{PERFORMANCE OF VERTICAL GRAVITATIONAL FLASH TANK}

The performance of the vertical gravitational flash tank separator can be identified by the liquid separation efficiency. The liquid separation efficiency is a ratio between the liquid mass flow rate at the liquid outlet of the separator and the total liquid mass flow rate at the inlet of separator [3]. To identify experimentally liquid separation efficiency, the liquid mass flow rate at the inlet and liquid mass flow rate at the liquid outlet of the vertical flash tank need to be measured [15]. In addition, pressure and temperature at the inlet and outlets of the vertical flash tank separators also need to be measured to estimate the vapour quality at the inlet and gas outlet of the vertical flash tank separator [16]. The liquid separation efficiency can be calculated as follows.

$\tau_{\mathrm{L}}=\frac{\mathrm{m}_{\mathrm{L}, \text { outlet }}}{\mathrm{m}_{\mathrm{L}, \text { inlet }}}=\frac{\mathrm{m}_{\mathrm{L}, \text { outlet }}}{\mathrm{m}_{\mathrm{t}}(1-\mathrm{x})}$

In the experiments of this work, no vapour bubbles were visually detected within the column of liquid at the bottom of the flash tank at the liquid outlet [15]. Thus, it is assumed that there was no vapour leaving the flash tank through the liquid outlet. Under 
these conditions, the liquid separation efficiency $\eta$ is sufficient to specify the separation performance of the vertical flash tank separator.

\section{TEST SECTION}

The basic body of the vertical flash tank separator (VFT-V5) has a $50 \mathrm{~mm}$ internal diameter and $5 \mathrm{~mm}$ wall thickness. The vertical flash tank separators were built with a height of $250 \mathrm{~mm}$, as shown in Figure 1 [15]. The separator has two outlets: the liquid outlet, which is at the bottom of the tank and has a $10 \mathrm{~mm}$ inside diameter $\mathrm{d}_{\mathrm{L} \text {-out }}$; and the gas outlet, which is at the top of the tank and also has a $10 \mathrm{~mm}$ inside diameter $\mathrm{d}_{\mathrm{G} \text {-out. }}$ The appropriate length of the inlet tube of the vertical flash tank separator has been identified as $300 \mathrm{~mm}$ which was determined from a previous experiment which is related to present study. The vertical flash tank separator was constructed using a transparent acrylic pipe to allow visual inspection. In order to connect the liquid and gas outlets with the body of the flash tank separator, aluminium flanges with O-rings were fabricated. The aluminium flanges enable convenient swapping of separators when required. The inlet tube with an internal diameter $\mathrm{d}=25 \mathrm{~mm}$ was connected with the separator at the centre of the separator's body height.

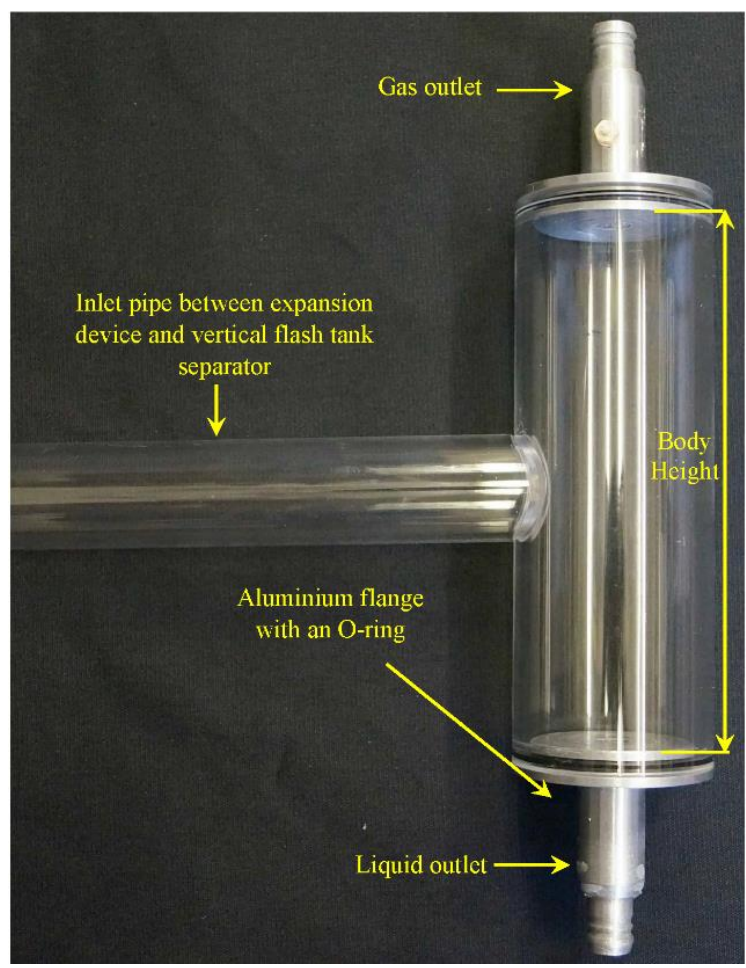

Figure 1. Configuration of the basic body of the vertical flash tank separator (VFT-V5).

\section{Proposed Design}

The proposed design is designated VFT-V5-EXR and involves the addition of an extractor inside the VFT-V5 separator at the gas outlet. The extractor is a very simple design, and it is used to extract or eliminate the liquid drops that move with the gas through the gas outlet [17]. However, a special proposed design of an extractor was used in the present work [15]. The dimensions of the proposed extractor were finalised using 
CFD simulation in order to obtain a high separation performance. A range of extractor diameters was simulated in CFD, and according to the highest predicted liquid separation efficiency, an $18.53 \mathrm{~mm}$ radius was selected. Figure 2 presents the final dimensions of the proposed design. The extractor was printed using polylactic acid (PLA) material. The extractor was connected to the top flange of the gas flow outlet after machining the inside diameter of the existing flange to fit the $12 \mathrm{~mm}$ diameter and the $20 \mathrm{~mm}$ long spigot of the printed extractor. Figure 3 shows the configuration of VFT-V5-EXR and the position of the extractor through a section view from a 3D model. The VFT-V5EXR was installed in the experimental apparatus and tested under the experimental operating conditions.

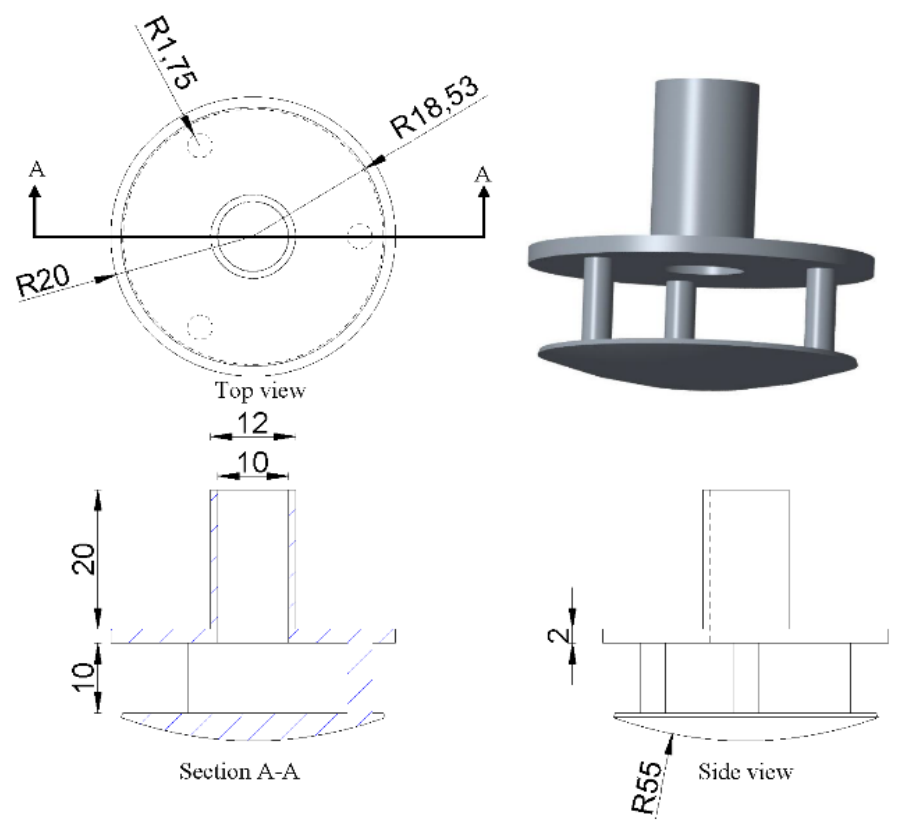

Figure 2. Dimension and illustration of the extractor.

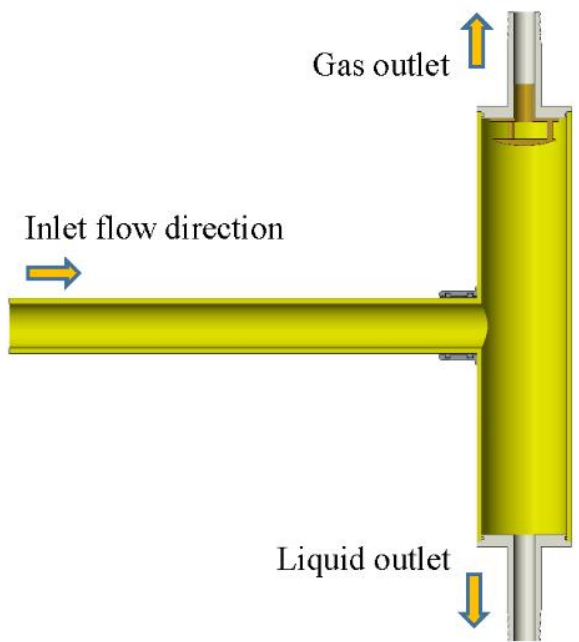

(a)

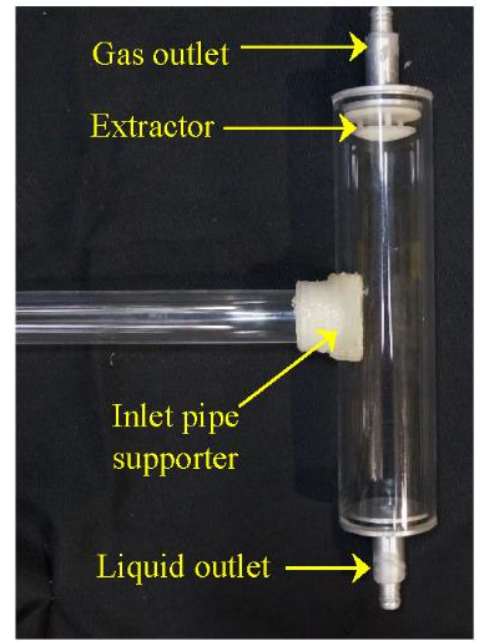

(b)

Figure 3. Configuration of VFT-V5-EXR: (a) section view from 3D model, (b) photograph of the assembly. 


\section{EXPERIMENTAL APPARATUS}

A schematic diagram of the facility used in the current study is presented in Figure 4. The facility was designed and built in such a manner to investigate the liquid separation efficiency of a vertical flash tank separator. The experimental apparatus consisted of the test section vertical flash tank separator, vacuum pump, condenser, heat exchanger and expansion device. Measurements including video recordings, were used to ascertain the temperature, pressure and mass flow rate in the vertical flash tank separator. All the measurement sensors were connected to the data acquisition equipment [15]. As the working fluid was water in this study, a special design was used for the expansion device. VisiJet crystal (EX 200 material) was used to fabricate the expansion device using a 3D printer model ProJetTM SD \& HD 3500. The VisiJet material has a limited maximum working temperature of around $65{ }^{\circ} \mathrm{C}$. The expansion device was designed to provide a uniform two-phase flow distribution across the horizontal pipe inlet port of the vertical flash tank separator; Figure 5 presents the configuration of the special design of the expansion device. A digital camera was used to record the flow behaviour inside the vertical flash tank separator.

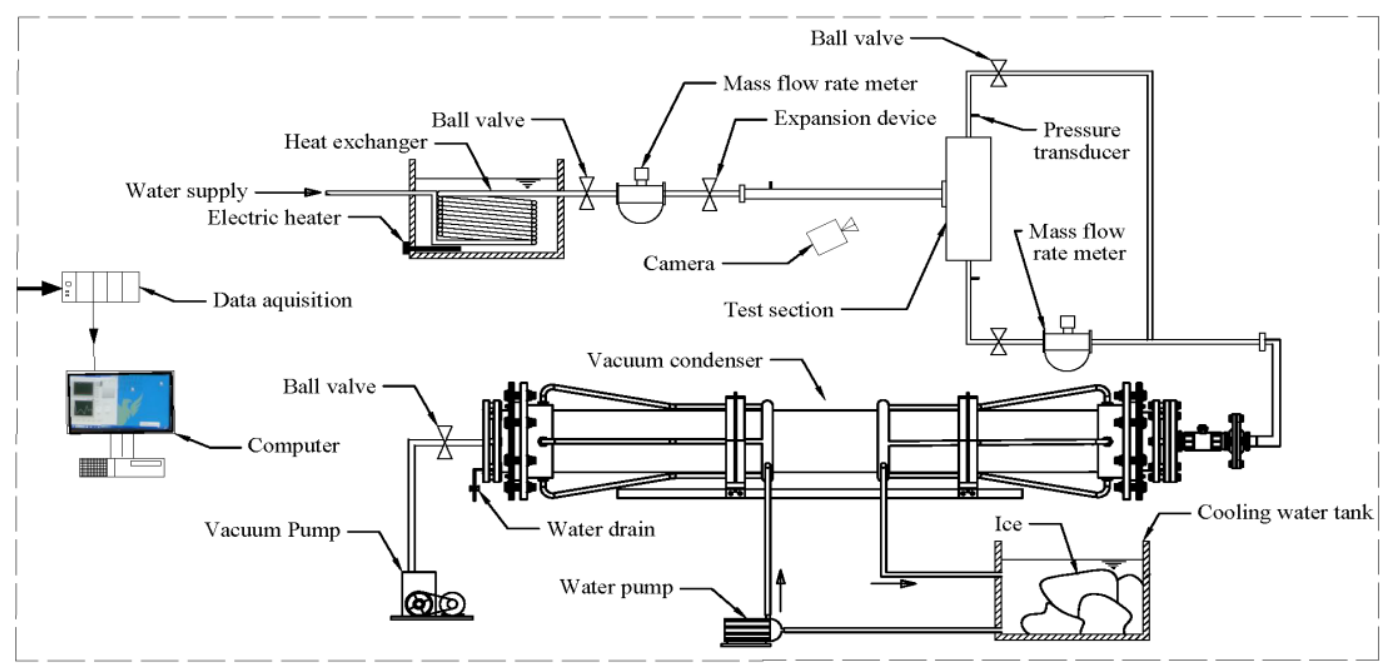

Figure 4 Schematic diagram of the vertical tank separator experimental apparatus.

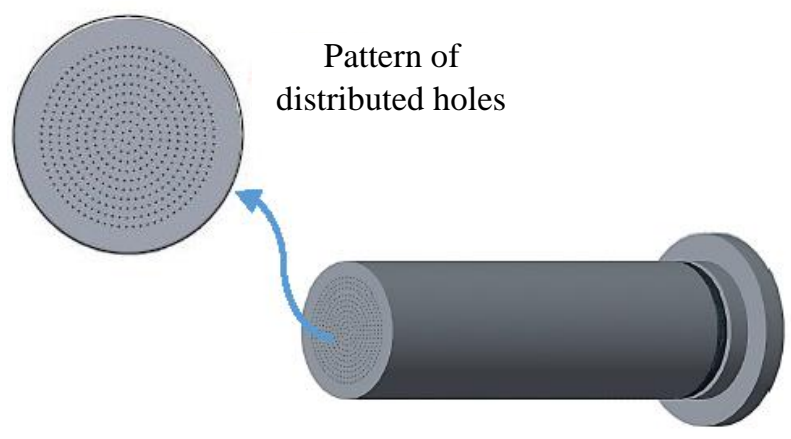

Figure 5 Configuration of the expansion device. 


\section{Experiment Uncertainty}

In the experiments, the systematic uncertainty of the measured parameters was considered according to the manufacture data of the instruments. Three parameters were directly measured in the experiments: mass flow rate, pressure and temperature. All the measurement instruments were calibrated before running the experiments; the calibration test report of the instruments was provided by the manufacturers [15]. Table 1 shows the designated uncertainty of the instruments based on manufacturer's data. Therefore, error bars have been used to denote the estimated uncertainty of the liquid separation efficiency due to the mass flow rate measurements from the experimental data.

\section{Operating Conditions}

Based on the working fluid (water) which was used in this study, the special design of the expansion device and limitations of the apparatus, a range of mass flow rates was used in the vertical flash tank experiments: 2.1 to $23.4 \pm 0.2 \mathrm{~g} / \mathrm{s}$, under gravity effect. According to the mass flow rate range and pressure drop across the expansion device, the vapour quality after the expansion device was calculated to be in the vicinity $5 \%$. Table 2 presents the experimental operating conditions for vertical ash tank experiments.

Table 1. Manufactures designated uncertainty of the measurement instruments.

\begin{tabular}{lccc}
\hline Measured parameters & Instrument type & Operating range & Uncertainty $( \pm)$ \\
\hline $\mathrm{P}$ & Wika 10-A & $0-100 \mathrm{kPa}$ & $0.5 \mathrm{kPa}$ \\
\hline $\mathrm{T}$ & RTD (PT100) & $-50-+200{ }^{\circ} \mathrm{C}$ & $0 .{ }^{\circ} \mathrm{C}$ \\
& $\begin{array}{c}\text { Thermocouple } \\
\text { (Type K) }\end{array}$ & $0-+200{ }^{\circ} \mathrm{C}$ & $0.75{ }^{\circ} \mathrm{C}$ \\
\hline$\dot{\mathrm{m}}_{\text {total }}$ & Siemens & Max $3700 \mathrm{~kg} / \mathrm{h}$ & $0.2 \mathrm{~g} / \mathrm{s}$ \\
\hline$\dot{\mathrm{m}}_{\text {Loutlet }}$ & Yokogawa & Max $1500 \mathrm{~kg} / \mathrm{h}$ & $0.1 \mathrm{~g} / \mathrm{s}$ \\
\hline
\end{tabular}

Table 2. Experimental operating conditions.

\begin{tabular}{lcccccc}
\hline Parameter & Case 1 & Case 2 & Case 3 & Case 4 & Case 5 & Case 6 \\
\hline $\begin{array}{l}\text { Inlet mass flow rate } \\
( \pm 0.21 \mathrm{~g} / \mathrm{s})\end{array}$ & 2.1 & 5.1 & 8.1 & 10.2 & 13.1 & 23.4 \\
$\begin{array}{l}\text { Inlet temperature } \\
( \pm 1.6 \mathrm{C})\end{array}$ & 21.4 & 21.8 & 22 & 22.4 & 22.7 & 23.5 \\
$\begin{array}{l}\text { Pressure drop across the } \\
\text { expansion device } \\
( \pm 0.15 \mathrm{kPa})\end{array}$ & 8.4 & 18.3 & 24.7 & 36.5 & 45.9 & 94.1 \\
$\begin{array}{l}\text { Inlet pressure } \\
( \pm 0.55 \mathrm{kPa})\end{array}$ & 2.54 & 2.61 & 2.64 & 2.71 & 2.76 & 2.82 \\
$\begin{array}{l}\text { Vapour quality }( \pm 0.6 \%) \\
\begin{array}{l}\text { Pressure at liquid outlet } \\
( \pm 0.52 \mathrm{kPa})\end{array}\end{array}$ & 5.6 & 5.5 & 5.5 & 5.4 & 5.3 & 5.3 \\
$\begin{array}{l}\text { Pressure at gas outlet } \\
( \pm 0.52 \mathrm{kPa})\end{array}$ & 2.05 & 2.12 & 2.15 & 2.22 & 2.27 & 2.33 \\
\hline
\end{tabular}


The vapour quality can be used to identify the dryness or wetness of the mixture in the two-phase flow regime.

$\mathrm{x}=\frac{\mathrm{m}_{\mathrm{g}}}{\mathrm{m}_{\mathrm{t}}}$

$\mathrm{m}_{\mathrm{t}}=\mathrm{m}_{\mathrm{g}}+\mathrm{m}_{\mathrm{i}}$

$\mathrm{m}_{\mathrm{g}}=\mathrm{GAx}$

$\mathrm{m}_{\mathrm{i}}=\mathrm{GA}(1-\mathrm{x})$

Vapour quality defines the proportions of the liquid and vapour phases in the mixture, and it also can be calculated from thermodynamic properties such as enthalpy. For example,

$\mathrm{x}=\frac{\mathrm{h}-\mathrm{h}_{\mathrm{f}}}{\mathrm{h}_{\mathrm{fg}}}$

Where $h_{f}$ is the saturated liquid enthalpy, $h_{f g}=h_{g}-h_{f}$ is the difference between the specific enthalpy of the saturated vapour and saturated liquid, and $h$ is the mixture specific enthalpy which can be defined as

$h=\frac{h_{f} m_{i}+h_{g} m_{g}}{m_{i}+m_{g}}$

In the experiments, the vapour quality at the inlet port after the expansion device was calculated based on the pressure and enthalpy values. The enthalpy across the expansion device was assumed constant because the process in the expansion device is a throttling process which was assumed to be adiabatic. The local atmospheric pressure in the laboratory was approximately $93.8 \mathrm{kPa}$.

\section{CFD TWO-PHASE FLOW MODELLING}

ANSYS 17.1 FLUENT was used to simulate the gas-liquid two-phase flow of the present work. The Eulerian model with gravity effect was used because the flow regime is a gasliquid two-phase flow: and the phases are firstly mixed well directly after the expansion device; then these phases are separated. The k- $\varepsilon$ turbulence model was used for each phase to represent the turbulence in the present work. The Eulerian model is appropriate for the gas-liquid two-phase flow [18]. Many numerical simulations of gas-liquid two-phase flow have used the Eulerian model in different geometries including sudden expansion [19] and flow in a horizontal tube [20], [21] because it is more accurate than the Volume of Fraction (VOF) and Mixture models [19]. In the Eulerian approach, the liquid phase and vapour phase are both treated as a continuous phase by using the volume fraction for each phase [22]. The Eulerian two-phase model solves a set of two-phase differential equations for each phase, so it is the most complex of the two-phase models [19]. Consequently, the computational effort required for the solution of the Eulerian model is higher than that in the VOF and Mixture models because the number of transport equations that need to be solved in Eulerian model is higher than that in the VOF and Mixture models. 


\section{Computational Domain}

The domain of the vertical flash tank geometry was created in the 3D mode with the exploitation of the symmetry plane, as shown in Figure 6. The geometry was taken from the experimental configuration presented in Figure 1.

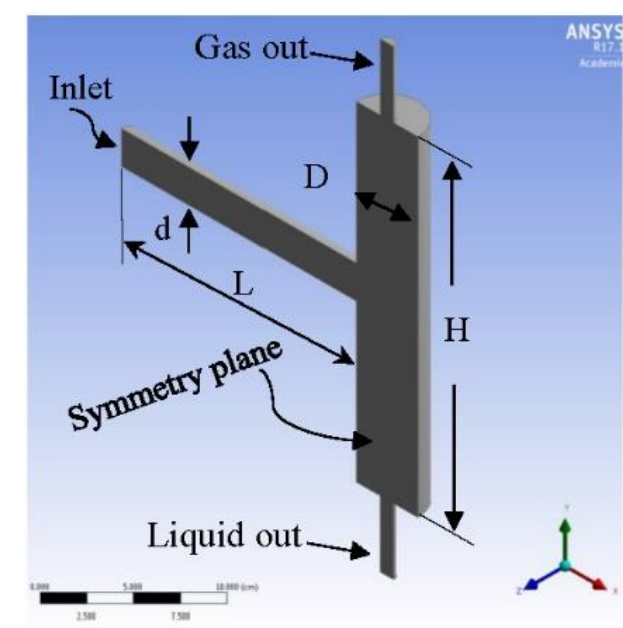

Figure 6. 3D domain geometry configuration of the vertical flash tank separator.

\section{Boundary Conditions}

In order to generate simulations consistent with the experimental data, the same operating conditions were used in the CFD simulation. Water was used as the working fluid. At the inlet, the liquid droplet size was selected according to the expansion device design, which has 400 holes with $0.3 \mathrm{~mm}$ diameter, so the liquid droplet diameter was selected to be $300 \mu \mathrm{m}$.

On the assumption that homogeneous flow is formed directly after the expansion device, the velocity at the inlet of the horizontal tube can be calculated based on the homogeneous void fraction [23]. The liquid velocity was calculated from

$\mathrm{u}_{1}=\frac{\mathrm{m}_{\mathrm{i}}}{\rho_{\mathrm{l}} \mathrm{A}\left(1-\alpha_{\mathrm{hg}}\right)}$

Where the A is the total cross-section area of the horizontal pipe, $\rho_{1}$ is the liquid density, $\dot{\mathrm{m}} \mathrm{l}$ is the liquid mas flow rate and $\alpha_{\mathrm{hg}}$ is the homogeneous gas void fraction which can be calculated from:

$\alpha_{\mathrm{hg}}=\left[1+\left(\frac{1-\mathrm{x}}{\mathrm{x}}\right)\left(\frac{\rho_{\mathrm{g}}}{\rho_{\mathrm{l}}}\right)\right]^{-1}$

Similarly, the gas velocity at the inlet was calculated from

$u_{\mathrm{g}}=\frac{\mathrm{m}_{\mathrm{g}}}{\rho_{\mathrm{g}} \mathrm{A} \alpha_{\mathrm{hg}}}$

Where the $\rho_{\mathrm{g}}$ is the gas density, $\dot{\mathrm{m} g}$ is the gas mass flow rate. 
The inlet boundary condition was specified as uniform velocity distribution for each phase at the inlet of the vertical flash tank. A pressure outlet was used for the outlet boundary condition. The no-slip wall was applied for the wall boundary. Gravity effect was activated.

\section{Mesh Independence Study}

The meshes created for the vertical flash tank simulations were created from tetrahedral elements which have benefits such as reduced computational time and improved mesh quality for three-dimensional domains of complex shapes [24]. The meshes were generated and optimised using Ansys Meshing. An unstructured grid was obtained using global and local sizing parameter after a series of tests. The mesh quality can be represented by three factors: orthogonal quality, aspect ratio, and skewness value [24]. The orthogonal quality ranges from 0 to 1 and 0 represents low mesh quality. The minimum orthogonal quality should always be greater than or equal to 0.01 [22]. The aspect ratio is relevant to the wall function and should be small enough to allow the solution to capture the flow details near the wall [25]. The skewness value, which is inversely related to solution accuracy, should be small enough to minimise error in the solution [26]. For the meshes used in the present simulations, the orthogonal quality was 0.9 , with a minimum value of 0.07 , the aspect ratio was 3.56 , and skewness value was 0.26 . These values indicate that according to the established criteria, good mesh qualities were obtained and used in the present simulations. The geometry of the vertical flash tank was discretised into tetrahedral elements, and in order to generate a fine mesh near the walls and around the extractor, the inflation method was used. Figure 7 illustrates the mesh of the vertical flash tank. Four computational grids of 8500, 180000, 220000 and 280000 elements were used to investigate the grid independence in the vertical flash tank case. The operating condition $\mathrm{m}=13.1 \mathrm{~g} / \mathrm{s}$ and $\mathrm{x}=5.4 \%$ was used to simulate the liquid separation efficiency for the different element number meshes. The geometry of the VFTV5-EXR was used to investigate the mesh number effect on liquid separation efficiency.

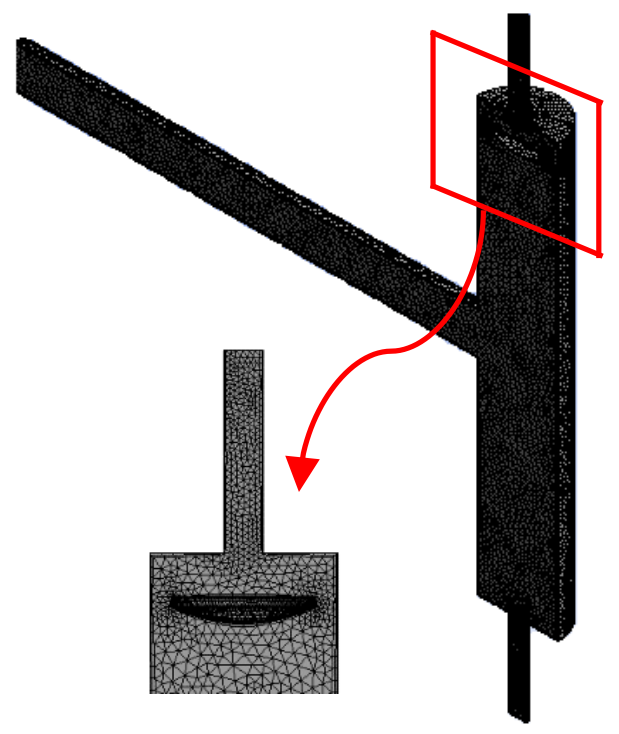

Figure 7 Vertical flash tank mesh with inflation near the walls for the 220000 element mesh case. 
Figure 8 shows an assessment of grid independence for the vertical flash tank separator, showing the variation of the liquid separation efficiency for different mesh elements. In this figure, the result for the 220000 and 280000 elements is close, and the difference between them is 0.001 . While the maximum difference of 0.401 was recorded between 8500 and 280000. As can be seen from Figure 8, the simulations using the two highest numbers of mesh elements achieved convergence with very low variation. In addition, the 280000 mesh elements did not change the convergence significantly compared to the mesh with 220000 elements. Therefore, the number of mesh elements selected for the primary simulations of the vertical flash tank separator of the present work was 220000.

Figure 9 illustrates the liquid volume fraction (LVF) distribution to present the significant effect of the grid on the resolution of the interface for the two-phase flow. The red area represents the liquid film at the bottom of the pipe, and the transitional colours between the red and blue represent the interface between the phases. It can be seen that there is no significant change in the liquid volume fraction and the smoothing of the interface between the liquid and vapour when the mesh number increased beyond 220000 .

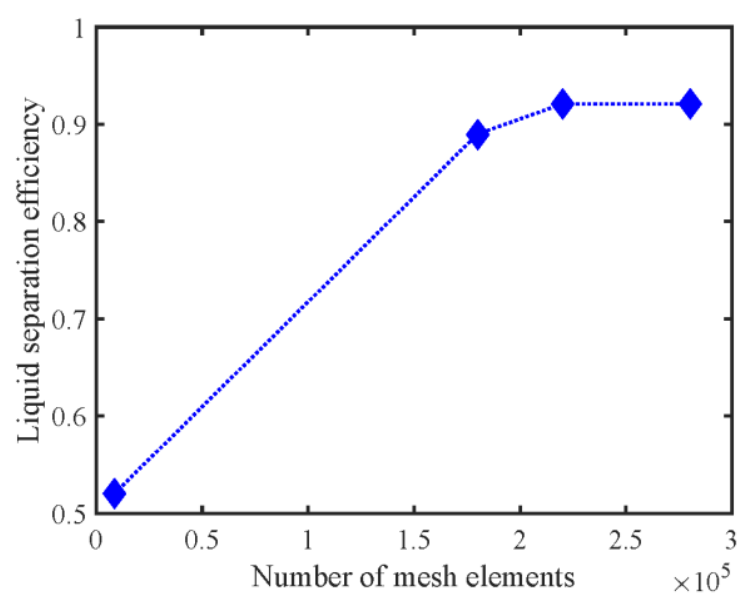

Figure 8 Assessment of grid independence for the vertical flash tank showing the variation of liquid separation efficiency with number of mesh element at $\mathrm{m}=13.1 \mathrm{~g} / \mathrm{s}$ and $\mathrm{x}=5.4 \%$.

\section{RESULTS AND DISCUSSION}

The experiments revealed that at low inlet mass flow rate, the liquid entered the separator at a sufficiently low velocity that the liquid stream fell towards the liquid outlet on entering the separator and there was no liquid stream impingement on the vertical side of the separator opposite the inlet. However, small liquid drops were still observed on the separator's wall and inlet pipe. When the inlet mass flow rate was increased, the liquid stream had a sufficiently high velocity that it impinged on the vertical wall of the flash tank separator as illustrated in Figure 10. 


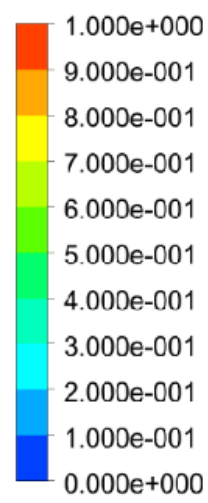

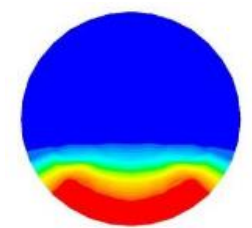

Mesh 8500

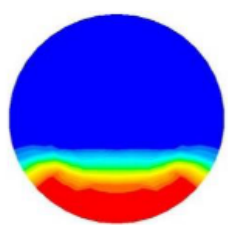

Mesh 180000

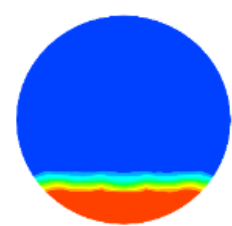

Mesh 220000

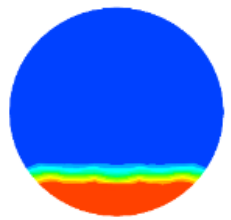

Mesh 280000

Figure 9 Assessment of grid independence showing liquid volume fraction contours for different element numbers in the inlet of the vertical flash tank separator at the developed region, (100 $\mathrm{mm}$ from the inlet of the separator at $\dot{\mathrm{m}}=10.2 \mathrm{~g} / \mathrm{s}, \mathrm{x}=5.2 \%$ ).

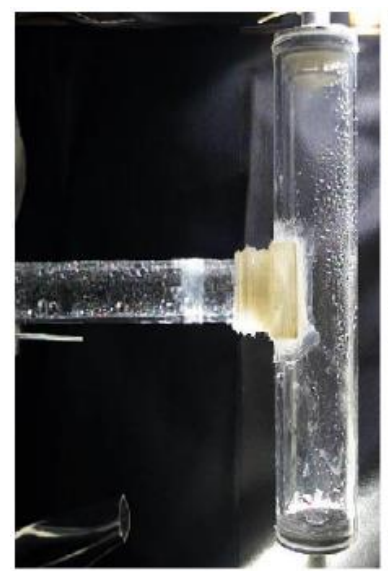

$\dot{m}=2.1 \pm 0.2 \mathrm{~g} / \mathrm{s}$

Flow direction

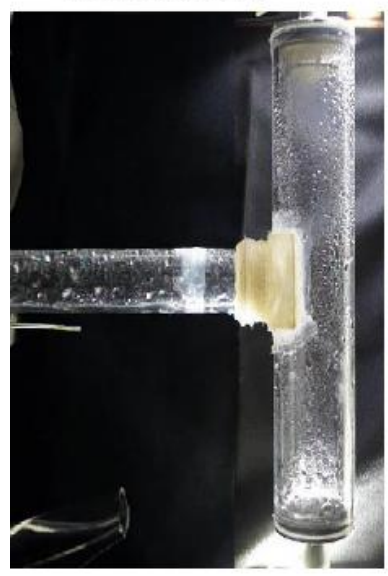

$\dot{m}=10.2+0.2 \mathrm{~g} / \mathrm{s}$

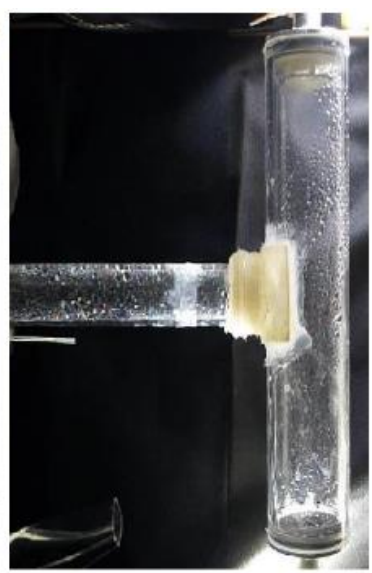

$\dot{m}=5.1+0.2 \mathrm{~g} / \mathrm{s}$

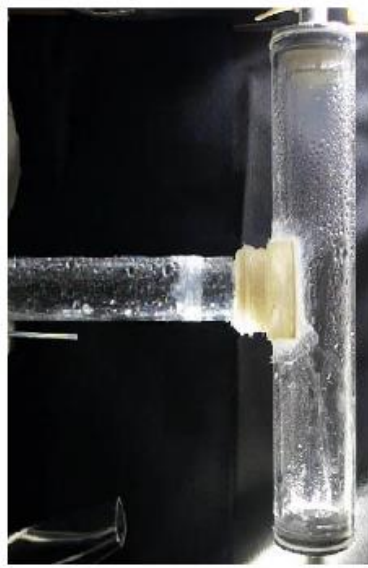

$\dot{m}=13.1 \pm 0.2 \mathrm{~g} / \mathrm{s}$

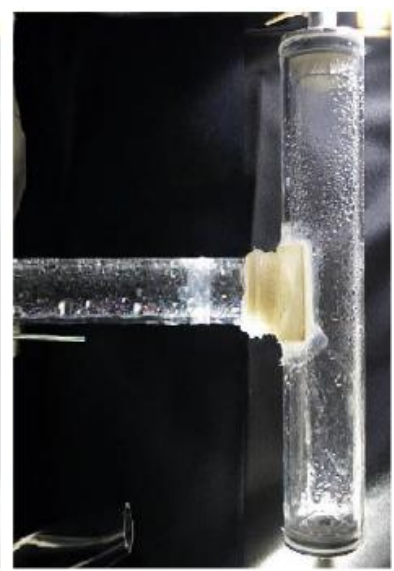

$\dot{m}=8.1 \pm 0.2 \mathrm{~g} / \mathrm{s}$

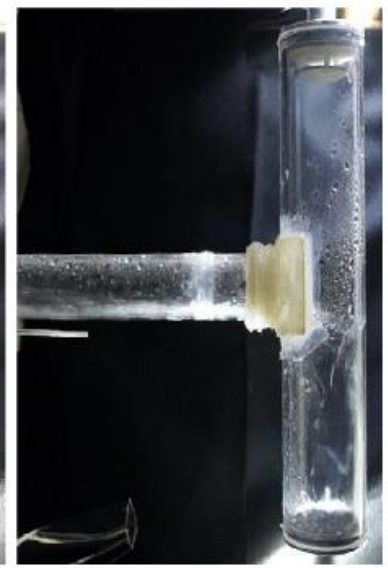

$\dot{m}=23.4 \pm 0.2 \mathrm{~g} / \mathrm{s}$

Figure 10 Images of the modified vertical flash tank separator VFT-V5-EXR during operation. Inlet flow direction is from left to right. 
Figure 11 presents the numerical and experimental results for the liquid separation efficiency of the VFT-V5-EXR. The error bars denote the estimated uncertainty of the efficiency due to the mass flow rate measurements from the experimental data. The highest value of the uncertainty inefficiency in the experiments for the vertical tank was about \pm 0.058 . The CFD gives the same trend as the experiment but has a lower magnitude by about 0.02 . The extractor affects liquid drops that move with the gas towards the gas outlet by causing impingement of liquid drops onto the extractor followed by coalescence into droplets large enough to disengage from the bottom of the extractor and drop through the rising gas flow into the liquid holding part of the separator as shown in Figure 12. As can be seen, in each case, there are some liquid drops on the inner wall of the upper half of the separator due to the drag force effect and impingement of the incoming stream. The observed flow pattern at the inlet of the vertical separator was a stratified flow at all of these operating conditions.

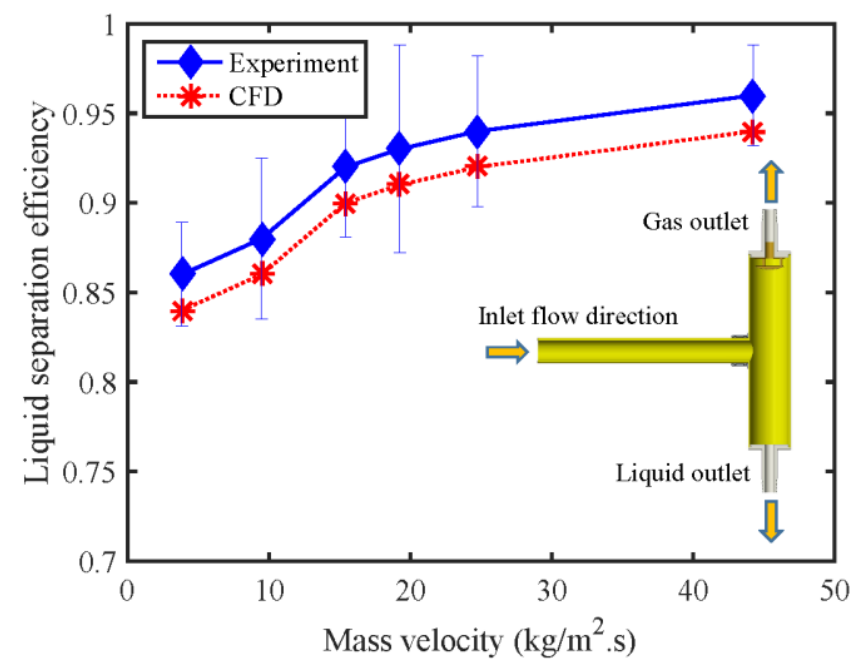

Figure 11 Comparison between CFD and experimental results for VFT-V5-EXR.

\section{Liquid Separation Efficiency}

Figure 13(a) and 13(b) present the experimental and numerical simulation results respectively. Generally, the liquid separation efficiency is increased by increasing the inlet mass flow rate. The VFT-V5-EXR configuration is more efficient: the results revealed that the liquid separation efficiency is $2 \%$ higher than that in the VFT-V5 configuration. The extractor is effective in extracting the liquid drops at the gas outlet at all operating conditions. Therefore, using the extractor with downward flow orientation in the VFT-V5-ODEXR gives the highest value of the separation performance of the vertical flash tank separator. 


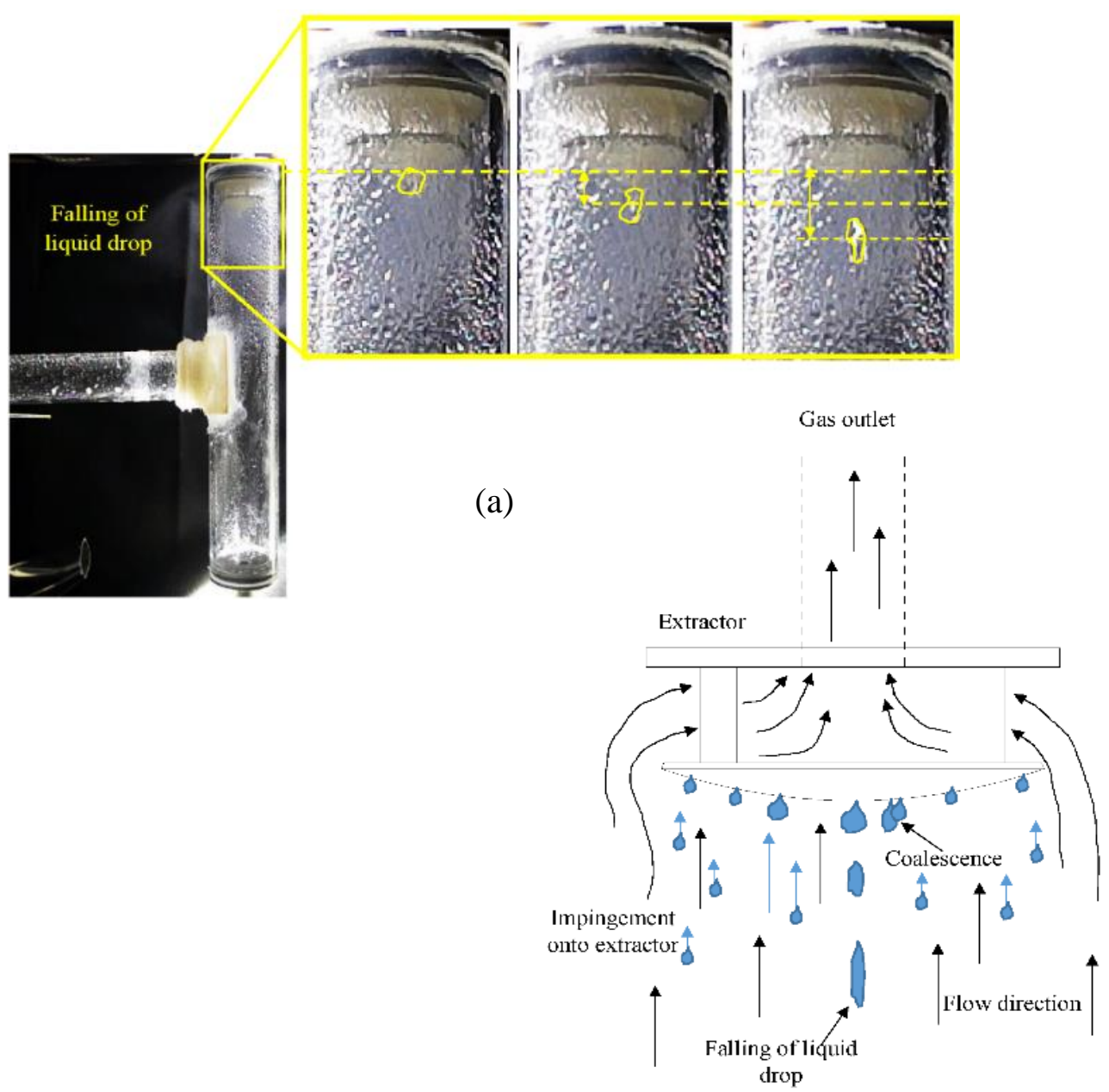

(b)

Figure 12. Impingement of droplets coalescence, and detachment (a) sequence of frames showing a liquid drop falling and; (b) sketch illustrating the key processes in the extractor.

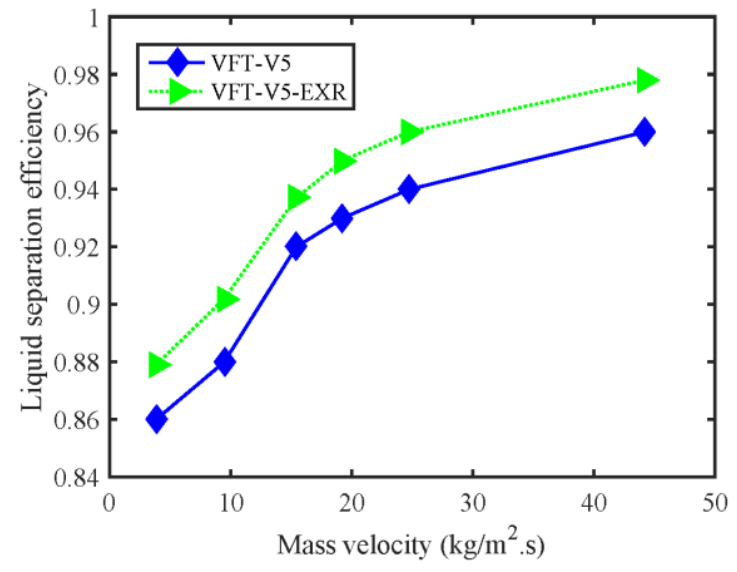

(a)

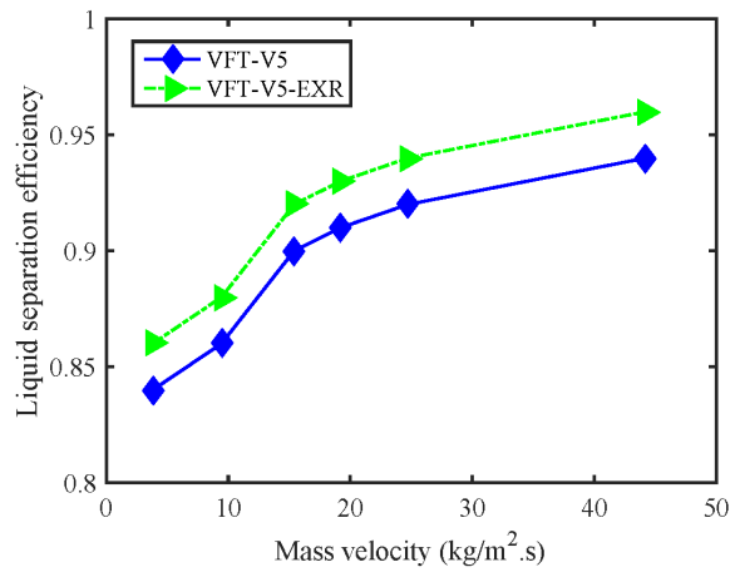

(b)

Figure 13 (a) Experimental and; (b) CFD results comparing the VFT-V5 and the enhanced design configuration VFT-V5-EXR. 


\section{Vapour Quality at the Gas Outlet}

Figure 14 presents the experimental results for the vapour quality at the gas outlet of the vertical separator across all operating conditions of the enhanced efficiency configurations and the reference VFT-V5 configuration. The vapour quality has been increased because of applying the extractor technique to the vertical flash tank separator. The results revealed that the highest value of the vapour quality was achieved by the VFTV5-EXR. Figure 13 also confirms that the extractor can reduce the number of the liquid drops that move with the gas through the gas outlet, so the vapour state in the VFT-V5EXR is higher than that in VFT-V5 especially at high mass flow rates.

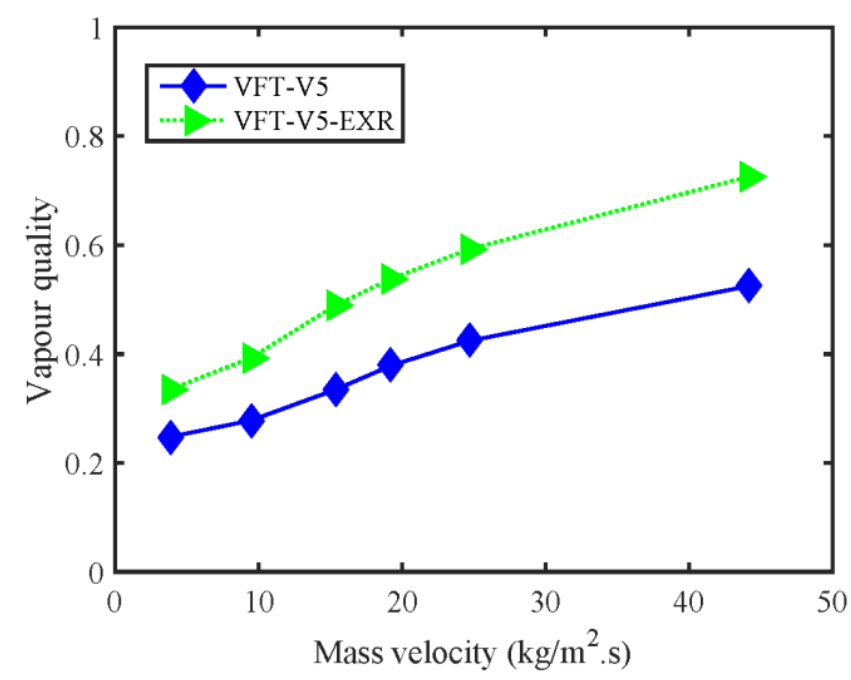

Figure 14. Experimental results for the vapour quality at the gas outlet of the separator for the VFT-V5 and VFT-V5-EXR configurations.

\section{CONCLUSION}

Numerical and experimental investigations to study the effect of using an extractor in the vertical gravitational flash tank separator have been performed. Using the extractor technique was shown to be effective in increasing the liquid separation efficiency. The liquid separation efficiency of the vertical gravitational flash tank separator has been calculated for a range of different mass flow rates. The numerical and experimental results can be summarised as follows:

i. The extractor increases the liquid separation efficiency by improving the removal of the liquid drops that move with the gas towards the gas outlet.

ii. At low inlet mass flow rate, the liquid entered the separator at a sufficiently low velocity that the liquid stream fell towards the liquid outlet on entering the separator and there was no liquid stream impingement on the vertical side of the separator opposite the inlet.

iii. The extractor affects liquid drops that move with the gas towards the gas outlet by causing impingement of liquid drops onto the extractor followed by coalescence into droplets large enough to disengage from the bottom of the extractor and drop through the rising gas flow into the liquid holding part of the separator.

iv. The vapour quality at the gas outlet was also improved by the extractor. 
v. A reasonable agreement obtained between the experimental and numerical results, with the CFD typically under-predicting the liquid separation efficiency by between $1 \%$ and $2 \%$ over the range of conditions tested.

\section{REFERENCES}

[1] Mohanraj M, Jayaraj S, Muraleedharan C. Environment friendly alternatives to halogenated refrigerants-A review. International Journal of Greenhouse Gas Control. 2009;3:108-19.

[2] Han X-H, Qiu Y, Xu Y-J, Zhao M-Y, Wang Q, Chen G-M. Cycle performance studies on a new HFC-161/125/143a mixture as an alternative refrigerant to R404A. Journal of Zhejiang University - Science A. 2012;13:132-9.

[3] Hanfei T, Hrnjak P. Experimental study of refrigerant two phase separation in a compact vertical T-junction. ASHRAE Transactions. 2012;118:672-80.

[4] Sirwan R, Alghoul MA, Sopian K, Ali Y, Abdulateef J. Evaluation of adding flash tank to solar combined ejector-absorption refrigeration system. Solar Energy. 2013;91:283-96.

[5] GPSA. Engineering Data Book. Tulsa, USA: Gas Processors and Suppliers Association; 2004.

[6] Grodal Ed, Evert and Realff, Matthew. Optimal design of two-and three-phase separators: A mathematical programming formulation. SPE Annual Technical Conference and Exhibition 1999.

[7] Wang SK. Air conditioning and refrigeration engineering. Boca Raton: CRC Press; 2000.

[8] Mo S, Chen X, Chen Y, Yang Z. Passive control of gas-liquid flow in a separator unit using an apertured baffle in a parallel-flow condenser. Experimental Thermal and Fluid Science. 2014;53:127-35.

[9] Zheng N, Zhao L, Hwang Y, Zhang J, Yang X. Experimental study on two-phase separation performance of impacting T-junction. International Journal of Multiphase Flow. 2016.

[10] Grodal E, Realff M. Optimal design of two-and three-phase separators: A mathematical programming formulation. SPE Annual Technical Conference and Exhibition 1999.

[11] Jekel TB, Reindl DT. Gravity separation fundumentals and design. IIAR 2001 Ammonia Refrigeration Convention \& Exhibtion. Long Beach CA2001.

[12] Xiong Z, Lu M, Wang M, Gu H, Cheng X. Study on flow pattern and separation performance of air-water swirl-vane separator. Annals of Nuclear Energy. 2014;63:138-45.

[13] Zarrouk SJ, Purnanto MH. Geothermal steam-water separators: Design overview. Geothermics. 2015;53:236-54.

[14] Misiulia D, Elsayed K, Andersson AG. Geometry optimization of a deswirler for cyclone separator in terms of pressure drop using CFD and artificial neural network. Separation and Purification Technology. 2017;185:10-23.

[15] Mahmood RA. Experimental and computational investigation of gravity separation in a vertical flash tank separator University of Southern Queensland; 2018.

[16] Mahmood RA, Buttsworth D, Malpress R. Computational and experimental investigation of the vertical flash tank separator part 1: Effect of parameters on 
separation efficiency. International Journal of Air-Conditioning and Refrigeration. 2019;27.

[17] Campbell JM. Gas Conditioning and Processing. 9th ed. Norman Oklahoma USA: Campbell Petroleum Series; 2004.

[18] Cheng L, Ribatski G, Moreno Quibén J, Thome JR. New prediction methods for CO2 evaporation inside tubes: Part I - A two-phase flow pattern map and a flow pattern based phenomenological model for two-phase flow frictional pressure drops. International Journal of Heat and Mass Transfer. 2008;51:111-24.

[19] Roul MK, Sahoo LK. CFD modeling of pressure drop caused by two-phase flow of oil/water emulsions through sudden expansions. International Journal of Numerical Methods for Heat \& Fluid Flow. 2012;2:1047-54.

[20] Walvekar RG, Choong TS, Hussain S, Khalid M, Chuah T. Numerical study of dispersed oil-water turbulent flow in horizontal tube. Journal of Petroleum Science and Engineering. 2009;65:123-8.

[21] Roman AJ, Kreitzer PJ, Ervin JS, Hanchak MS, Byrd LW. Flow pattern identification of horizontal two-phase refrigerant flow using neural networks. International Communications in Heat and Mass Transfer. 2016;71:254-64.

[22] FLUENT A. 14.5, Theory Guide; ANSYS. Inc, Canonsburg, PA. 2012.

[23] El Hajal J, Thome JR, Cavallini A. Condensation in horizontal tubes, part 1: twophase flow pattern map. International Journal of Heat and Mass Transfer. 2003;46:3349-63.

[24] Vallée C, Höhne T, Prasser H-M, Sühnel T. Experimental investigation and CFD simulation of horizontal stratified two-phase flow phenomena. Nuclear Engineering and Design. 2008;238:637-46.

[25] Ellison T, Hatziavramidis D, Sun B, Gidaspow D. Computational fluid dynamics (CFD) model for phase separation at branching tee junctions. SPE Western Regional Meeting 1997.

[26] Desamala AB, Dasari A, Vijayan V, Goshika BK, Dasmahapatra AK, Mandal TK. CFD simulation and validation of flow pattern transition boundaries during moderately viscous oil-water two-phase flow through horizontal pipeline. International Journal of Chemical, Materials Science and Engineering. 2013; 7(1):1-6. 